\title{
MiR-543 Promotes Proliferation and Epithelial-Mesenchymal Transition in Prostate Cancer via Targeting RKIP
}

\author{
Yang Du ${ }^{\mathrm{a}}$ Heng-cheng Zhu ${ }^{\mathrm{b}}$ Xiu-heng Liu ${ }^{\mathrm{b}}$ Lei Wang ${ }^{\mathrm{c}}$ Jin-zhuo Ning ${ }^{\mathrm{c}}$ \\ Cheng-cheng $\mathrm{Xiao}^{\mathrm{c}}$ \\ aDepartment of Urology, Renmin Hospital of Wuhan University, Hubei, ${ }^{b}$ Department of Urology, Renmin \\ Hospital of Wuhan University, Hubei, 'Department of Urology, Renmin Hospital of Wuhan university, \\ Hubei, China
}

\section{Key Words}

miR-543 • RKIP • Prostate cancer • Metastasis • Proliferation

\begin{abstract}
Background/Aims: MicroRNAs (miRNAs, miRs) have emerged as important posttranscriptional regulators in various cancers. miR-543 has been reported to play critical roles in hepatocellular carcinoma and colorectal cancer, however, the role of miR-543 in the pathogenesis of prostate cancer has not been fully understood. Methods: Expression of miR-543 and Raf Kinase Inhibitory Protein (RKIP) in clinical prostate cancer specimens, two prostate cancer cell lines, namely LNCAP and C4-2B, were determined. The effects of miR-543 on proliferation and metastasis of tumor cells were also investigated with both in vitro and in vivo studies. Results: miR-543 was found to be negatively correlated with RKIP expression in clinical tumor samples and was significantly upregulated in metastatic prostate cancer cell line C4-2B compared with parental LNCAP cells. Further studies identified RKIP as a direct target of miR-543. Overexpression of miR-543 downregulated RKIP expression and promoted the proliferation and metastasis of cancer cells, whereas knockdown of miR-543 increased expression of RKIP and suppressed the proliferation and metastasis of cancer cells in vitro and in vivo. Conclusion: Our study demonstrates that miR-543 promotes the proliferation and metastasis of prostate cancer via targeting RKIP.

\section{Introduction}

Prostate cancer ( $\mathrm{PCa}$ ) is currently the most common malignancy worldwide and the second leading cause of cancer-related death in males [1]. Although, thus far, early prostate

Y. Du and H.-c. Zhu contributed equally to this work.

Xiu-heng Liu, PhD, Full Professor,

KARGER
Department of Urology, Renmin Hospital of Wuhan University, Jiefang Road 238 Wuhan, Hubei, 430060 (China)

Tel. (86)027-88041911, Fax +(86)027-88042292, E-Mail phoenixneo@126.com 


\section{Cellular Physiology Cell Physiol Biochem 2017;41:1135-1146 \begin{tabular}{ll|l} 
DOI: 10.1159/000464120 & (0) 2017 The Author(s). Published by S. Karger AG, Basel \\
and Biochemistry & Published online: February 28, 2017 & www.karger.com/cpb \\
\cline { 2 - 3 }
\end{tabular} \\ Du et al.: MiR-543 and RKIP in Prostate Cancer}

cancer can be radically cured, advanced or metastatic prostate cancer remains difficult to diagnose early and prevent. It has been reported that hormone therapy only maintains a median progression-free time of 2 years [2]. Hence, defining the mechanisms occurred in metastasis is important for us to better understand the progression of prostate cancer and helpful to identify therapeutic targets.

Raf kinase inhibitor protein (RKIP) is a homolog of the phosphatidylethanolamine binding protein (PEBP) family [3]. It has been identified as a competitive inhibitor of Rafmediated activation of mitogen-activated protein kinase/extracellular signal-regulated kinase (MAPK/ERK) [4]. RKIP is involved in various cellular activities and is widely expressed in brain, lung, liver, muscle and prostate [5-8]. Notably, it has been observed that loss of this protein is closely related to a range of human malignancies, including cancers of breast, lung, colon and prostate [9-13]. Some of these results have been verified in various in vitro and in vivo models $[14,15]$, which indicates that RKIP may function like a tumor suppressor in many systems.

MicroRNAs (miRNAs) are a class of endogenously expressed non-coding single-strand RNA molecules with a length of 20-24 nucleotides [16]. They negatively regulate the expression of target genes by post-transcriptionally binding to 3 '-untranslated-region [17, 18]. Their regulatory functions are involved in numerous biological processes, including differentiation, carcinogenesis and morphogenesis [19-21]. Accumulated evidence has suggested that miRNAs are tightly associated with proliferation and epithelial-mesenchymal transition (EMT) in tumor genesis [22-24]. For example, miR-200a is reported to suppress proliferation and metastasis through downregulation of DEK [25], miR-27a regulates cisplatin resistance and metastasis of human lung adenocarcinoma by targeting RKIP [10], and miR-129 increases cell invasion in prostate cancer by repressing CP110 [26]. A recent research has showed that miR-543 functions as an oncogene in hepatocellular carcinoma by targeting PAQR3 [27]. In addition, miR-543 has also been found to decrease the tumor suppressor AIMP3 in human stem cell by targeting AIMP3/p18 [28]. However, the biological effect of miR-543 in prostate cancer and the correlation between miR-543 and RKIP have not been elucidated.

In the current study, we found that miR-543 significantly increased in metastatic prostate cancer tissues. Then, we identified RKIP as a direct downstream target of miR543 and demonstrated, for the first time, that miR-543 is a key factor regulating the tumor growth and metastasis of prostate cancer by targeting RKIP, suggesting that miR-543 is likely to be used as a novel biomarker for predicting metastasis of prostate cancer.

\section{Materials and Methods}

\section{Clinical specimens}

The current study was approved by the Institutional Ethics Committee of Ren'min Hospital of Wuhan University. All of the prostate cancer specimens and adjacent normal tissues from patients with prostate cancer were collected from the Department of Urology, Ren'min Hospital of Wuhan University from 20152016. The relevant clinical information was collected from patients with prior informed written consent. All the specimens were divided into two parts, half were fixed in $4 \%$ paraformaldehyde, and the other half were frozen in liquid nitrogen and then reserved at $-80^{\circ} \mathrm{C}$. Tumor stage and grade were classified according to the tumor, node, metastasis(TNM) staging system of the American Joint Committee on Cancer (AJCC), Gleason score and preoperative PSA level (Table 1).

Cell Lines and Cell Culture

Human prostate cancer cell line LNCAP were obtained from ATCC (American Type Culture Collection, Manassas, VA) and cultured in RPMI 1640 medium. C4-2B cells were provided by Dr. Dalin He (Department of Urology, First Affiliated Hospital of Xi'an Jiaotong University, Xi'an) and were maintained in T medium with 80\% DMEM and 20\% Ham's F12 medium (GIBCO, MA, USA) and supplemented with 5\% FBS. 


\section{Cellular Physiology Cell Physiol Biochem 2017;41:1135-1146 \begin{tabular}{ll|l} 
and Biochemistry Published onIIne: February 28, 2017 & $\begin{array}{l}\text { (c) } 2017 \text { The Author(s). Published by S. Karger AG, Basel } \\
\text { www.karger.com/cpb }\end{array}$ \\
\hline
\end{tabular} Du et al.: MiR-543 and RKIP in Prostate Cancer}

Plasmid Construction and Transfection

The wild-type sequence of the RKIP 3'untranslated region (3'UTR) containing predicted miR-543 target sites was amplified by PCR from LNCAP cell. The mutant 3'UTR sequence of RKIP was generated using an overlap-extension PCR method. Then, the sequences including the predicted wild and mutant target sites were subcloned into a psiCHECK-2 vector (Promega Corporation, Madison, WI) to synthesize the wild and mutant RKIP-3'UTR vectors.

MiR-543 mimics and negative control mimics (NC), miR-543 inhibitors (anti-miR-543) and negative control inhibitors (anti-NC), miR543 angomir and antagomir, and RKIP siRNAs (5'- CAGCCACTTTCGCTATTCTTGTGTT-3') were constructed by Biossci Company (Wuhan, China). Transfections were performed using Lipofectamine 2000 (Invitrogen, CA, USA), following the instructions of manufacturer. Cells were harvested after 48 hours for further analyses.

\section{Luciferase Reporter Assays}

After being seeded into a 24-well plate, LNCAP cells were co-transfected with miR-543 or control and RKIP-3'UTR-luciferase plasmids. After $48 \mathrm{~h}$, cells were collected and lysed. The luciferase activity was assessed by a Dual-Luciferase Reporter Assay System (Promega Corporation), and results were normalized to Renilla luciferase activity.

\section{Quantitative real-time PCR}

Total RNA was extracted from clinical specimens and cancer cells using Trizol Reagent (Invitrogen, CA, USA) according to the manufacturer's instructions. The RNA purity was examined by spectrophotometry. Then, cDNA of miRNA was synthesized from 100 ng of total RNA using TaqManH MicroRNA Reverse Transcription (ABI, CA) and cDNA of RNA was synthesized from TaqMan $1 \mu \mathrm{g}$ of total RNA using Reverse Transcription Reagents (ABI, CA). MiRNAs were reverse-transcribed using specific stem-loop RT primers; mRNAs were also reverse-transcribed by using random hexamers. Real-time quantitative PCR was performed using SYBRH Select Master Mix for CFX (Invitrogen). Relative quantification of each sample was obtained by normalization to the expression of GAPDH (for mRNAs) or snRNA U6 (for miRNAs). The relative amount of miRNA or mRNA was calculated via the $2^{-\Delta \Delta C t}$ method [29]. The primer sequences used are shown in Table 2.

\section{Western blot analysis}

All cells were lysed in RIPA-Buffer supplemented with 10 mM PMSF on ice for 30 minutes, followed by centrifugation at $16000 \mathrm{~g}$ for 10 minutes. A bicinchoninic acid assay (BCA) was performed to quantify protein concentrations. Briefly, equivalent weights of protein samples ( $40 \mu \mathrm{g} / \mathrm{lane}$ ) were separated on $10 \%$ sodium dodecyl sulfate-polyacrylamide gel electrophoresis (SDS-PAGE) and subsequently transferred to polyvinylidene fluoride (PVDF) membranes. After that, the membrane was blocked with 5\% nonfat milk in Tris-buffered saline and $0.1 \%$ Tween 20 buffer, then incubated with primary antibody against RKIP (\#13006, CST, USA), E-cadherin (\#14472, CST, USA), vimentin (\#5471, CST, USA) and $\beta$-actin (sc-1616, Santa Cruz, CA) at $4^{\circ} \mathrm{C}$ overnight. After being extensively washed with TBST buffer, membranes were incubated with secondary antibodies for 1 hour. All bands were treated with an enhanced chemiluminescence (ECL) system kit (MultiSciences, Hangzhou, China). Optical densities were detected by Image software (NIH, Bethesda, MD, USA). 


\section{Cellular Physiology Cell Physiol Biochem 2017;41:1135-1146

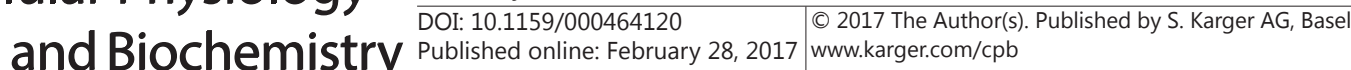 \\ Du et al.: MiR-543 and RKIP in Prostate Cancer}

Cell Proliferation Assay

Cells were inoculated into 96-well plates at a density of $2 \times 10^{3}$ cells/well directly or 24 hours after transfection. 48 hours later, cells were stained with $10 \mu \mathrm{L}$ of MTT dye per well $(5 \mathrm{mg} / \mathrm{ml}$, MultiSciences, Hangzhou, China) for 4 hours. Then, culture medium was removed followed by addition of $150 \mu \mathrm{L}$ of dimethyl sulfoxide (DMSO). The absorbance was detected at $490 \mathrm{~nm}$.

\section{Cell Invasion and Migration Assays}

Cell invasion and migration assays were performed using Transwell plates (Corning) with 8- $\mu$ m-pore size membranes with Matrigel (for invasion assay) or without Matrigel (for migration assay). Briefly, 3 x $10^{4}$ cells were seeded into the top of the chambers with serum free medium. In the lower chambers, medium containing $10 \%$ fetal bovine serum served as chemoattractant. 24 hours after incubation, cells on the top of membrane were wiped away. Then, the membrane were drenched in $95 \%$ ethanol for 30 minutes and subsequently stained with $0.2 \%$ crystal violet for 30 minutes. The migrating or invading cells were counted and photographed with an inverted microscope.

\section{Flow Cytometry Analysis}

Cell proliferation was additionally examined by cell cycle assay. Briefly, after been fixed in $70 \%$ ethanol at $48 \mathrm{~h}$ post-transfection, cells were treated with RNase A (50 $\mu \mathrm{g} / \mathrm{ml})$ and PI $(50 \mu \mathrm{g} / \mathrm{ml})$ (MultiSciences, China) for 30 min to undergo flow cytometry.

\section{Immunohistochemistry}

The expression of RKIP and E-cadherin was examined by immunohistochemical staining. Briefly, tissues were sliced into 3- $\mu \mathrm{m}$ sections and then deparaffinized. Subsequently, sections were incubated with rabbit monoclonal anti-RKIP $(1: 800 ; 13006$; CST, USA $)$ and rabbit monoclonal anti-E-cadherin $(1: 400 ; 3195$, CST, USA) antibodies at $4^{\circ} \mathrm{C}$ overnight. After washing three times with PBS, all sections were incubated with goat anti-rabbit IgG for $30 \mathrm{~min}$, then were stained with the color reagent 3,3'-diaminobenzadine (DAB).

\section{Animal studies}

All animal experiments were performed in accordance with the National Institutes of Health Guide for the Care and Use of Laboratory Animals, and approved by the Animal Care and Use Committee of Wuhan University. Six-week-old male BALB/c nude mice were purchased from the Animal Center of Ren'min hospital of Wuhan University. All mice were kept in a special pathogen free facility. For orthotopic metastasis, LNCAP cells (treated with either the miR-543 angomir or NC) and C4-2B cells (treated with either the miR543 antagomir or antagomir-NC) were inoculated into the prostate of nude mice ( $\mathrm{n}=5$ per group, $1 \times 10^{6}$ cells each). Mice with tumors were sacrificed four weeks later after inoculation. Primary tumor size was measured by caliper and tumor volume was calculated using the equation: Volume $=\left(\right.$ length * width $\left.{ }^{2}\right) / 2$ $\left(\mathrm{mm}^{3}\right)$. Transplanted tumors were dissected, half was used to perform hematoxylin \& eosin (H\&E) staining and the other was stored in liquid nitrogen for further analysis.

\section{Statistical Analysis}

All statistical analyses were carried out using SPSS 19.0 (SPSS, Chicago, IL) and Graphpad Prism 5.0. All data were expressed as means \pm SD. Differences were assessed by two-tailed Student's t test and $\chi^{2}$ test as appropriate. P values of 0.05 or less were considered as statistically significant.

\section{Results}

High expression of miR-543 in prostate cancer correlates with downregulation of RKIP

As the first step, we analyzed 42 prostate cancer specimens, which were examined by immunohistochemistry staining and qRT-PCR for the expression of RKIP and miR543 respectively (Fig. 1 A,B,C). Comparing to no-metastatic tissues, expression of RKIP significantly decreased in metastatic prostate cancer samples. However, the PCR results showed an inverse result, indicating that miR-543 expression dramatically increased in metastatic tumor tissues (Fig. 1 E,F). A two-tailed Pearson's correlation analysis was 


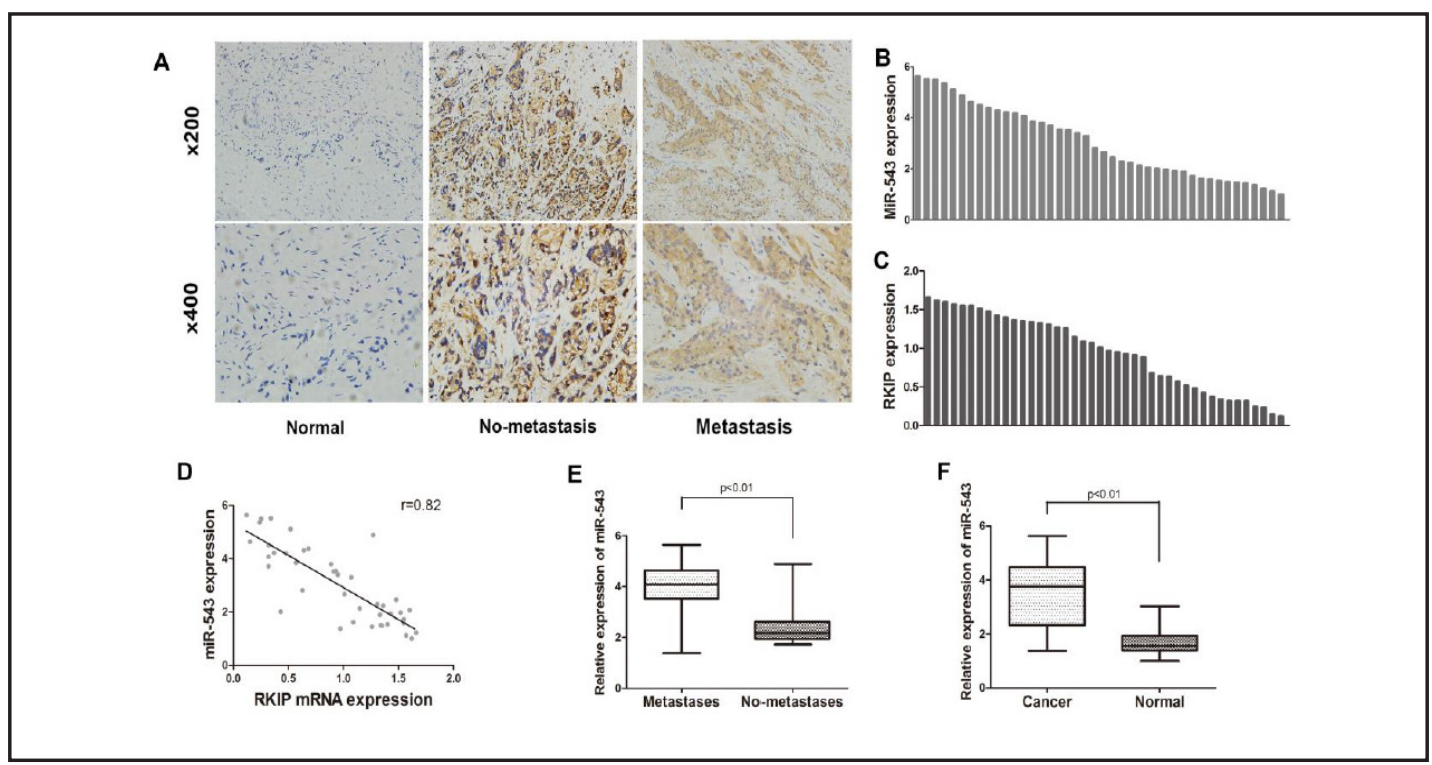

Fig. 1. High expression of miR-543 in prostate cancer correlates with downregulation of RKIP in clinical prostate cancer specimens. (A) Immunohistochemical analysis of RKIP in normal prostate tissue, no-metastasis PCa and metastasis PCa. (B) and (C) qRT-PCR analysis of miR-543 and RKIP mRNA expression in human PCa tissues from 42 patients with PCa. Data were expressed as $2^{-\Delta \Delta C t}$ fold change and were ranked from the highest to the lowest. (D) Clinical specimens analysis reveals that the expression of miR-27a is inversely correlated with the expression of RKIP. (E) Box plot represents relative miR-543 expression levels in metastatic PCa tissues and no-metastatic PCa tissues. (F) Relative miR-543 expression levels in PCa tissues and adjacent normal regions.

performed to further investigate the correlation between miR-543 and RKIP expression $(\mathrm{r}=0.82, \mathrm{P}<0.01)$ (Fig. $1 \mathrm{D})$. We found that miR-543 expression was inversely correlated to the expression of RKIP.

\section{RKIP expression is regulated by miR-543}

To further confirm the involvement of miR-543 in the regulation of RKIP expression that we observed in clinical specimens, we employed a non-metastatic and a derived metastatic prostate cancer cell line pair (LNCAP vs. C4-2B). Firstly, we measured miR-543 transcript by qRT-PCR and the expression of RKIP with western blotting (Fig. 2 A,B,C). Our data indicated C4-2B cells displayed a five to six fold higher expression of miR-543 and lower expression of RKIP than LNCAP cells. We then transfected LNCAP cells with miR-543 mimics and monitored RKIP expression by western blot. Interestingly, overexpression of miR-543 resulted in a significant downregulation of RKIP expression (Fig. 2 D,F). On the other hand, C4-2B cells transfected with a miR-543 inhibitor, displayed a moderate upregulation of RKIP expression (Fig. 2 E,G). Collectively, these data suggest that miR-543 promotes the expression of RKIP in prostate cancer.

\section{miR-543 directly targets RKIP}

To further explore the interaction between miR-543 and RKIP, an in silico prediction was performed using open access software (miRanda, TargetScan and PicTarget). A putative binding site for miR-543 was identified within the 3'UTR. To confirm this prediction, we cloned a fragment sequence in the 3'UTR of RKIP containing putative miR-543 binding sites into a luciferase reporter construct. Data from luciferase reporter assay revealed that the reporter vector activity of RKIP 3'UTR was significantly decreased in LNCAP cells upon miR543 overexpression. However, mutation of the putative miR-543 seed-binding regions in the 3'UTR of RKIP completely blocked this effect (Fig. 3 A,B). Together, these data indicated that RKIP is a direct target of miR-543.

\section{KARGER}


A

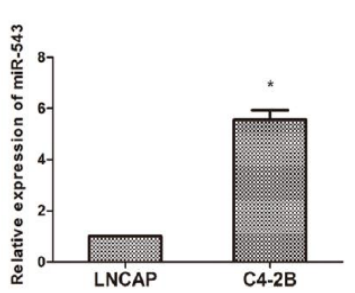

B

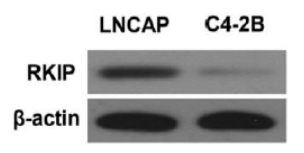

D

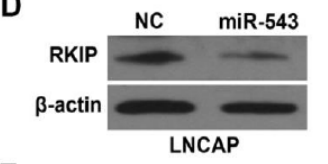

E

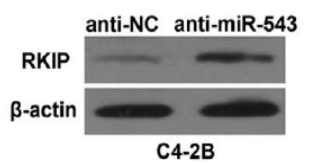

$\mathbf{F}$

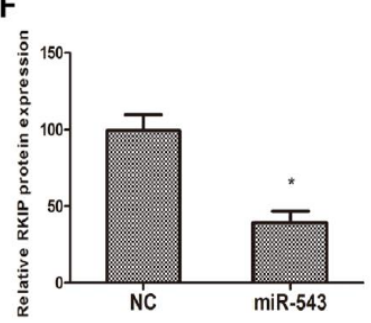

C

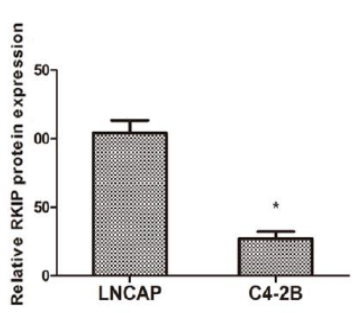

G

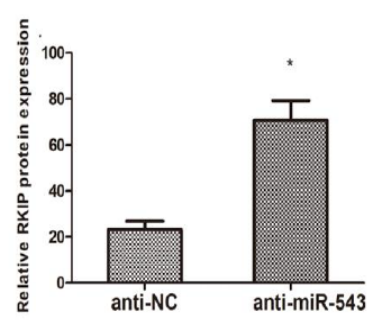

Fig. 2. RKIP expression is regulated by miR-543 in LNCAP and parental C4-2B cells. (A) qRT-PCR suggests that the expression of miR-543 is much higher in C4-2B cells compared with LNCAP cells. (B), (C) Western bolt analysis reveals that the expression of RKIP in C4-2B cells is significantly lower than in LNCAP cells. (D, F) and (E, G) LNCAP cells were transfected with NC or miR-543 mimics, C4-2B cells were transfected with anti-NC or miR-27a inhibitors respectively. Western blot analysis was performed to examine RKIP expression in LNCAP cells (D, F) and C4-2B cells (E, G). $\beta$-actin was used as an internal control. Data are presented as means \pm SD of three separated experiments $\left({ }^{*} \mathrm{P}<0.05\right)$.

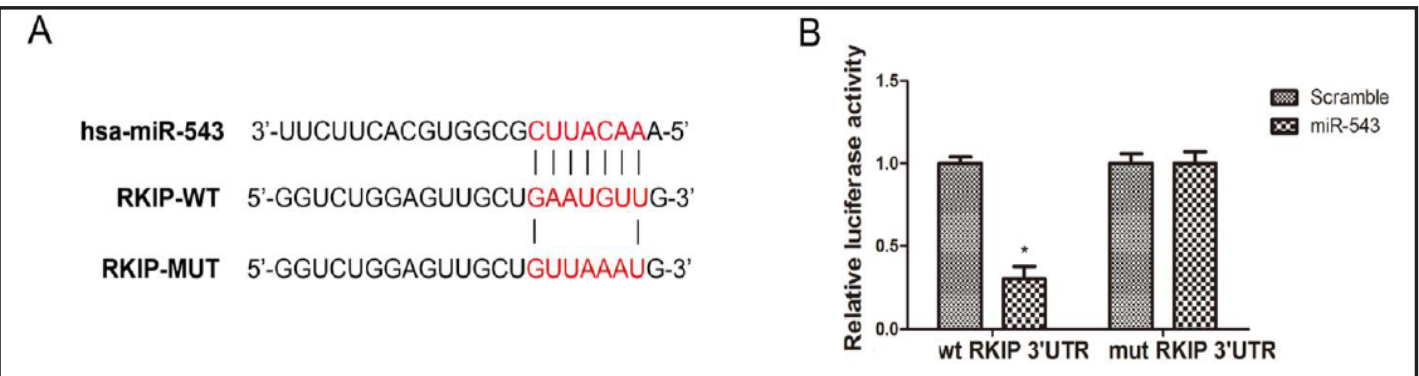

Fig. 3. RKIP is a direct target of miR-543. (A) Sequence alignment of predicted miR-543 binding sites within the RKIP 3'UTR and its mutated sequence for luciferase reporter assay. (B) Luciferase reporter assay was performed in LNCAP cells that were co-transfected with miR-543 mimics and reporter vectors containing RKIP 3'UTR or mutated RKIP 3'UTR. Relative luciferase activities are presented. MiR-543 repressed luciferase activities of reporter vectors. Data are shown as means \pm SD of three separated experiments $\left({ }^{*} \mathrm{P}<0.05\right)$.

MiR-543 promotes proliferation of prostate cancer cells via downregulation of RKIP in vitro

To delineate the role of miR-543 in prostate cancer progression, we compared the proliferation of LNCAP cells overexpressing miR-543 to that of C4-2B cells expressing a miR-543 inhibitor. Data from MTT assays suggested that compared with control group, overexpression of miR-543 in LNCAP cells dramatically increased the proliferation of tumor cell, while inhibition of miR-543 in C4-2B cells led to an inverse result (Fig. 4 A,B). Cell-cycle assays revealed that RKIP knockdown caused a significant increase of cell proliferation (Fig. 4 D). Subsequently, we transfected a vector which included the entire coding sequence of RKIP except the 3'UTR region into LNCAP cells with stable overexpression of miR-543. This construct was unable to bind with miR-543 and should therefore abolish the biologic effects caused by miR-543. As expected, ectopic expression of RKIP partially abolished miR-543mediated increase in cellular growth of LNCAP cells overexpressing miR-543 (Fig. 4 E,F). 


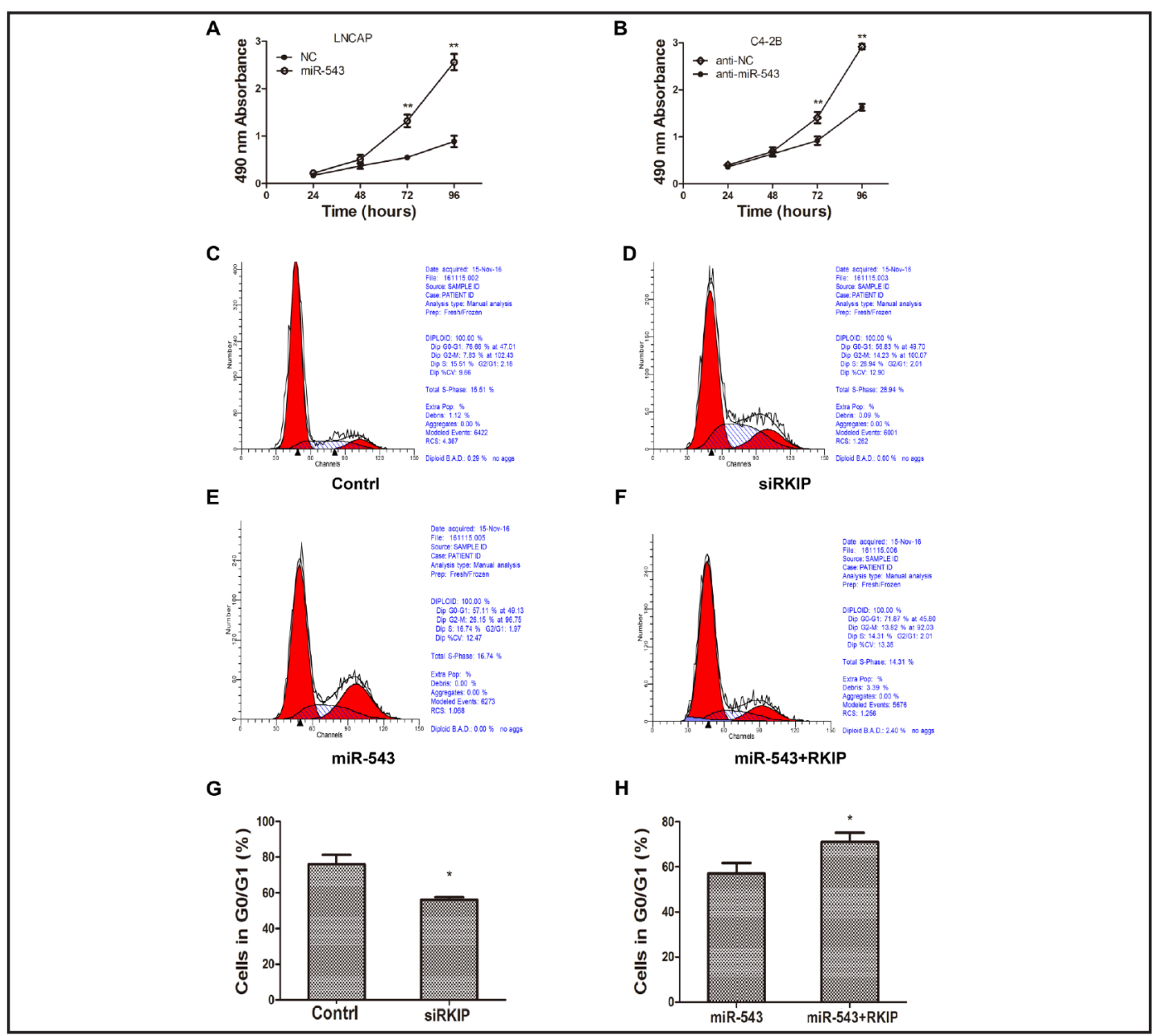

Fig. 4. MiR-543 promotes proliferation of prostate cancer cells via downregulation of RKIP in vitro. (A), (B), MTT assays was performed to analyze the proliferative variation after transfection with miR-543 mimics into LNCAP cells and transfection with miR-543 inhibitor into C4-2B cells. The absorbance value was detected at 24, 48, 72 and 96 hours post-transfection. (C), (D), (E), (F), (G), (H) Cell cycle assays were additionally performed to analyze cell proliferation of LNCAP cells after transfection with siRKIP, miR-543 mimics or plasmid lacking 3'UTR along with miR-543 mimics. (C), (D), (E), (F) Representative images of cell cycle assays. (G), (H) Average proportion of cells in G0/G1 phase. Data are presented as means \pm SD of three separated experiments $\left({ }^{*} \mathrm{P}<0.05,{ }^{* *} \mathrm{P}<0.01\right)$.

Taken together, these results revealed that miR-543 promotes cell growth of prostate cancer via downregulation of RKIP.

\section{MiR-543 induces EMT of prostate cancer via downregulation of RKIP in vitro}

To investigate the influence of miR-543 in the EMT progression of prostate cancer, LNCAP cells and C4-2B cells were transfected with miR-543 mimics or miR-543 inhibitor respectively. Data from Western blotting revealed that overexpressing of miR-543 decreased E-cadherin expression but increased vimentin protein levels in LNCAP cells (Fig. 5 E,G). Moreover, Transwell assays indicated that overexpression of miR-543 synergistically promoted the invasion and migration of LNCAP cells (Fig. $5 \mathrm{~A}, \mathrm{C}$ ). On the other hand, inhibition of miR-543 in C4-2B cells resulted in a moderate increase in E-cadherin and a decrease in vimentin levels (Fig. 5 F,H) and suppressed cell invasion and migration at the same time (Fig. 5 B,D). We then examined the role of RKIP in miR-543-induced EMT. First, we transfected LNCAP cells with si-RKIP and measured the protein levels of E-cadherin and 


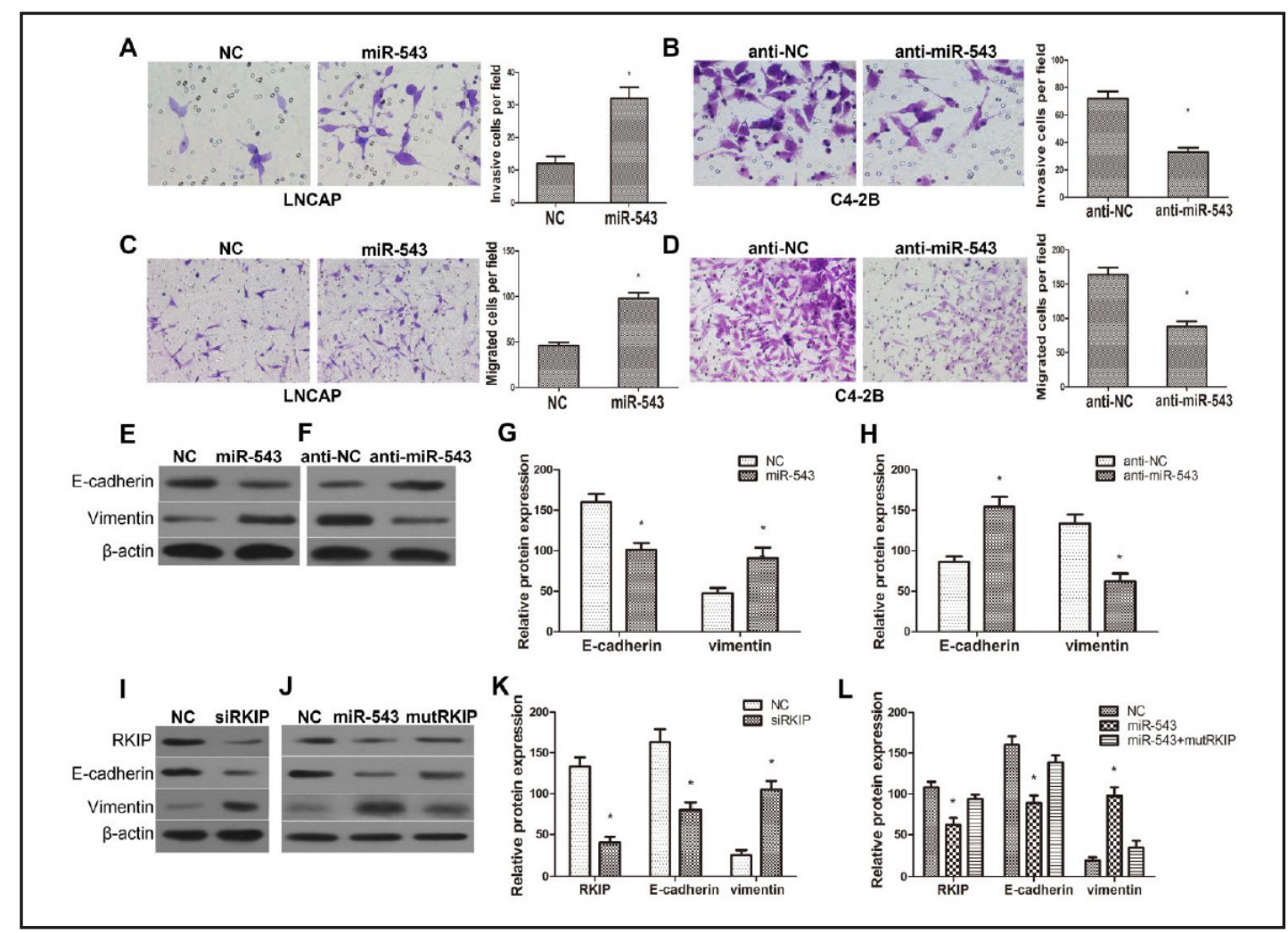

Fig. 5. MiR-543 mediates EMT of prostate cancer via downregulation of RKIP in vitro. (A), (B) Transwell invasion assays with Matrigel-coated membranes was performed to investigate the invasive ability of LNCAP cells after transfection with miR-543 mimics and C4-2B cells after transfection with miR-543 inhibitors. (C), (D) Transwell migration assays was performed to show the migratory ability of LNCAP cells transfected with miR-543 mimics and C4-2B cells transfected with miR-543 inhibitors. (E, G) and (F, H) E-cadherin and vimentin protein levels of LNCAP cells after transfection with miR-543 mimics and C4-2B cells after transfection with miR-543 inhibitors were detected by western blot analysis. (I), (K) RKIP, E-cadherin and vimentin protein levels in LNCAP cells transfected with RKIP siRNAs were examined by western blot analysis. (J), (L) RKIP, E-cadherin and vimentin protein levels in LNCAP cells transfected with NC, miR-543 mimics or plasmid lacking 3'UTR along with miR-543 mimics were examined by western blot analysis. $\beta$-actin was used as an internal control. Data are presented as means \pm SD of three separated experiments $\left({ }^{*} \mathrm{P}<0.05\right)$.

vimentin. Western blot showed that RKIP knockdown significantly decreased E-cadherin and increased vimentin (Fig. $5 \mathrm{I}, \mathrm{K}$ ). Then, plasmids expressing the entire sequence of RKIP without 3'UTR were transduced into LNCAP cells that overexpressed miR-543, and EMT was measured. We found that exogenous expression of RKIP partially abolished miR-543induced EMT (Fig. 5 J,L). Collectively, these results demonstrated that miR-543-induced EMT of prostate cancer cells is mediated by RKIP.

\section{MiR-543 promotes the proliferation and EMT of prostate cancer cells in vivo}

To further explore the effect of miR-543 expression on the proliferation and EMT of prostate cancer cells in vivo, LNCAP cells stably overexpressing miR-543 were orthotopically inoculated into nude mice for 4 weeks. Then, tumors were excised for analysis. qRT-PCR confirmed that miR-543 expression significantly increased in miR-543-overexpressing group compared with the control group. As we observed, mice inoculated with miR-543overexpressing cells formed larger tumors than control group (Fig. $6 \mathrm{~A}, \mathrm{C}$ ), and Western blotting revealed that the overexpressing group had a lower level of E-cadherin and a higher level of vimentin than control group (Fig.6 D). Next, we injected C4-2B cells with miR-543 antagomir into the prostates of nude mice for 4 weeks as well. As expected, suppression of 
A

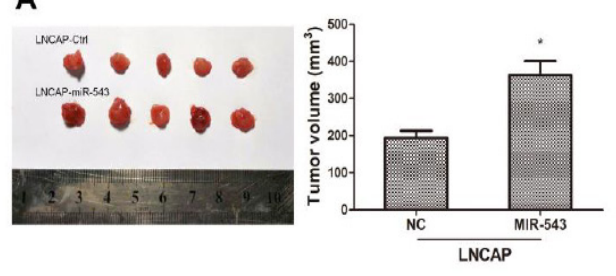

C

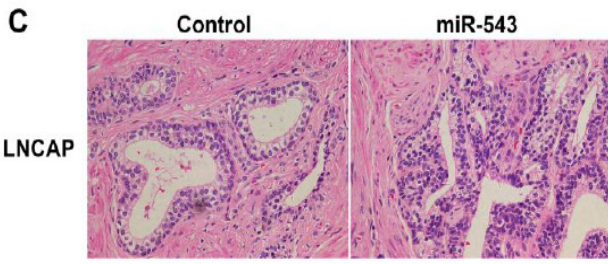

E

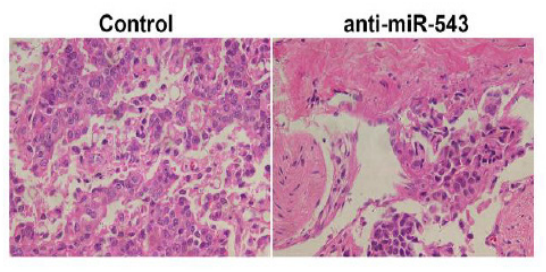

B
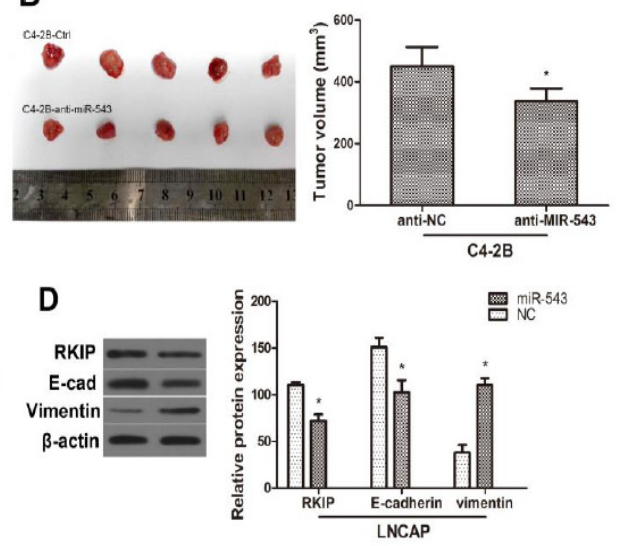

$\mathbf{F}$

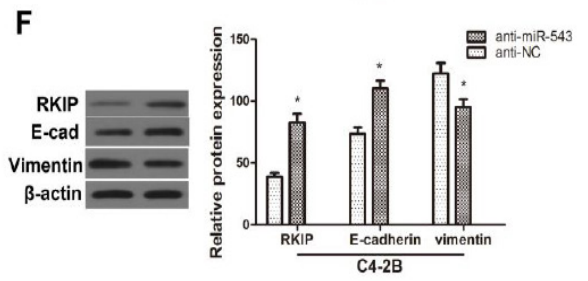

Fig. 6. MiR-543 regulates the proliferation and EMT of prostate cancer cells in vivo. (A) Images of isolated tumors derived 28 days after orthotropic injection in the prostate of nude mice with LNCAP-Ctrl or LNCAP-miR-543 cells (left), tumor volumes have been measured (right). (B) Images of isolated tumors derived 28 days after orthotropic injection in the prostate of nude mice with C4-2B-Ctrl or C4-2B-anti-miR-543 (left), tumor volumes have been measured (right). (C) HE staining of xenograft tumors from mice 28 days after injection with LNCAP-Ctrl and LNCAP-miR-543 cells. (E) HE staining of xenograft tumors from mice 28 days after injection with C4-2B-Ctrl and C4-2B-anti-miR-543 cells. (D) RKIP, E-cadherin and vimentin expression of xenograft tumors after injection with LNCAP-Ctrl and LNCAP-miR-543 cells was detected at protein level by western blot analysis. (E) RKIP, E-cadherin and vimentin expression of xenograft tumors after injection with C4-2B-Ctrl and C4-2B-anti-miR-543 cells was detected at protein level by western blot analysis. Data are presented as means \pm SD of three separated experiments $(* \mathrm{P}<0.05)$.

miR-543 mitigated tumor growth and EMT (Fig. 6 B, E, F). In sum, these results demonstrate that miR-543 promotes tumor growth and EMT of prostate cancer in vivo.

\section{Discussion}

Prostate cancer is mostly sensitive to androgen-deprivation therapy at the initial stage. However, along with disease progresses, the cancer cells gradually become insensitive and resistant to hormone treatment, and finally turn into castration resistant prostate cancer (CRPC) [30]. Thus far, the conventional clinical treatment of CRPC includes deferment of this progression by intermittent hormone therapy or alternative radiotherapy [31]. However, none of these treatments proved to be efficient for treating CRPC. Hence, it is important to dissect the molecular pathways that led to the metastasis of advanced prostate cancer and identification of these molecules may aid in developing more effective therapeutic approaches. Previous studies have indicated that miRNA can regulate tumor proliferation and metastasis in cancer cells by targeting to mRNA of specific genes [18]. Based on these results, we aimed to identify miRNAs that regulate the progression of prostate cancer.

MicroRNA expression is highly correlated with tumor proliferation and metastasis in various cancers. It has been demonstrated that aberrantly expressed miRNAs can regulate 


\section{Cellular Physiology Cell Physiol Biochem 2017;41:1135-1146 \begin{tabular}{ll|l} 
DOI: 10.1159/000464120 & (0) 2017 The Author(s). Published by S. Karger AG, Basel \\
and Biochemistry & $\begin{array}{l}\text { Published online: February 28, } 2017 \\
\text { www.karger.com/cpb }\end{array}$ \\
\cline { 2 - 3 }
\end{tabular} \\ Du et al.: MiR-543 and RKIP in Prostate Cancer}

RNA networks in tumor progression $[7,32,33]$. The same microRNA may function as a tumor suppressor or an oncogene in different contexts. MiR-543 is located to chromosome 14 and is highly conserved from murine to human. It has been reported that miR-543 promotes cell proliferation and metastasis in hepatocellular carcinoma, while it inhibited EMT through decreasing TWIST1 signaling in colorectal cancer [27, 34]. Furthermore, a recent study has also reported that miR-543 suppressed tumor growth and metastasis in colorectal cancer by targeting KRAS, MAT1 and HMGA2 [35]. However, the biological function and clinical significance of miR-543 in prostate cancer remains unclear. Here in the current study, we analyzed specimens from 42 patients with prostate cancer. Our data indicated that comparing to non-metastatic prostate cancer, miR-543 expression was significantly upregulated in metastatic prostate cancer and the higher expression of miR-543 negatively correlated with the expression of RKIP. Subsequently, we identified RKIP as a direct downstream target of miR-543 utilizing in silico prediction and a luciferase reporter assay.

It has been reported that RKIP gene is downregulated in various cancers which contributes to proliferation and metastasis of cancer cells through multiple pathways $[9,36]$. For example, RKIP suppresses invasion and metastasis of prostate cancer by inhibiting MAP kinase (MAPK) signaling [3]. Besides, RKIP mediates G-protein function and suppresses NF$\kappa B$ activation [37]. Moreover, RKIP sensitizes both prostate cancer cells and breast cancer cells to apoptosis, and decreases radio-resistance of prostate cancer cells [15, 38]. In our in vitro studies, we employed the no-metastatic prostate cancer cell line (LNCAP) and metastatic prostate cancer cell line (C4-2B) to simulate the progression of prostate cancer and further confirmed the inverse correlation between RKIP and miR-543 expression in the above two cell lines. Then, we established miR-543 stable overexpressing and silencing cell lines. We found that overexpression of miR-543 suppressed RKIP by direct binding to the 3'UTR of RKIP. Meanwhile, inhibition of miR-543 caused a significant upregulation in RKIP. Taken together, these data demonstrated that miR-543 negatively regulates the expression of RKIP in prostate cancer cells, which is in agreement with the observations from clinical samples.

Metastasis is the formation of secondary tumor foci at sites different or remote from the primary site [39]. Epithelial-mesenchymal transition is a major mechanism that contributes to the escape of metastatic cancer cells from the primary tumor. In our in vitro studies, we showed that overexpression of miR-543 promoted cell proliferation and EMT, while inhibition of miR-543 led to an opposite effect. Furthermore, data from the in vivo studies demonstrated that increased expression of miR-543 resulted in an increased tumor size and upregulation of genes that promotes EMT. This phenotype was partially rescued by silencing miR-543. Collectively, these data suggest miR-543-mediated inhibition of RKIP is associated with cell proliferation and EMT in prostate cancer.

\section{Conclusions}

In conclusion, we identified an inverse correlation between miR-543 expression and human prostate cancer cell lines with different metastatic abilities. Additionally, we demonstrated that miR-543 induced cell proliferation and epithelial-mesenchymal transition of prostate cancer by direct targeting RKIP both in vitro and in vivo. These findings suggest that miR-543 has the potential to be a novel biomarker in the prediction of metastasis in prostate cancer.

\section{Acknowledgement}

This study was supported by Application and Basic Research Project Of Wuhan City(No. 2015060101010049), Hubei Province Health and Family Planning Scientific Research Project(No. WJ2017M025 and No. WJ2017Z005 ) and the Bureau of Public Health of Hubei Province(No. JX6B62) 


\section{Cellular Physiology Cell Physiol Biochem 2017;41:1135-1146 \begin{tabular}{ll|l} 
DOI: 10.1159/000464120 & O 2017 The Author(s). Published by S. Karger AG, Basel \\
and Biochemistry & Publisned onnne:-Feoruary 28, 2017 www.karger.com/cpb
\end{tabular} Du et al.: MiR-543 and RKIP in Prostate Cancer}

\section{Disclosure Statement}

All author declare no conflicts of interest.

\section{References}

1 Siegel RL, Miller KD, Jemal A: Cancer statistics, 2015. CA Cancer J Clin 2015;65:5-29.

$\checkmark 2$ Harris WP, Mostaghel EA, Nelson PS, Montgomery B: Androgen deprivation therapy: Progress in understanding mechanisms of resistance and optimizing androgen depletion. Nat Clin Pract Urol 2009;6:76-85.

3 Yeung K, Seitz T, Li S, Janosch P, McFerran B, Kaiser C, Fee F, Katsanakis KD, Rose DW, Mischak H, Sedivy JM, Kolch W: Suppression of Raf-1 kinase activity and MAP kinase signalling by RKIP. Nature 1999;401:173-

177.

4 Yeung K, Janosch P, McFerran B, Rose DW, Mischak H, Sedivy JM, Kolch W: Mechanism of suppression of the Raf/MEK/extracellular signal-regulated kinase pathway by the raf kinase inhibitor protein. Mol Cell Biol 2000;20:3079-3085.

5 Frayne J, Ingram C, Love S, Hall L: Localisation of phosphatidylethanolamine-binding protein in the brain and other tissues of the rat. Cell Tissue Res 1999;298:415-423.

6 Bollengier F, Mahler A: Localization of the novel neuropolypeptide h3 in subsets of tissues from different species. J NeuroChem 1988;50:1210-1214.

7 Zhang H, Wu J, Keller JM, Yeung K, Keller ET, Fu Z: Transcriptional regulation of RKIP expression by androgen in prostate cells. Cell Physiol Biochem 2012;30:1340-1350.

8 Lin X, Bai F, Nie J, Lu S, Lu C, Zhu X, Wei J, Lu Z, Huang Q: Didymin alleviates hepatic fibrosis through inhibiting ERK and PI3K/Akt pathways via regulation of raf kinase inhibitor protein. Cell Physiol Biochem 2016;40:1422-1432.

-9 Hagan S, Al-Mulla F, Mallon E, Oien K, Ferrier R, Gusterson B, Garcia JJ, Kolch W: Reduction of Raf-1 kinase inhibitor protein expression correlates with breast cancer metastasis. Clin Cancer Res 2005;11:7392-7397.

10 Li J, Wang Y, Song Y, Fu Z, Yu W: MiR-27a regulates cisplatin resistance and metastasis by targeting RKIP in human lung adenocarcinoma cells. Mol Cancer 2014;13:193.

11 Al-Mulla F, Hagan S, Behbehani AI, Bitar MS, George SS, Going JJ, Garcia JJ, Scott L, Fyfe N, Murray GI, Kolch W: Raf kinase inhibitor protein expression in a survival analysis of colorectal cancer patients. J Clin Oncol 2006;24:5672-5679.

12 Fu Z, Smith PC, Zhang L, Rubin MA, Dunn RL, Yao Z, Keller ET: Effects of raf kinase inhibitor protein expression on suppression of prostate cancer metastasis. J Natl Cancer Inst 2003;95:878-889.

13 Keller ET, Fu Z, Yeung K, Brennan M: Raf kinase inhibitor protein: A prostate cancer metastasis suppressor gene. Cancer Lett 2004;207:131-137.

14 Escara-Wilke J, Keller JM, Ignatoski KM, Dai J, Shelley G, Mizokami A, Zhang J, Yeung ML, Yeung KC, Keller ET: Raf kinase inhibitor protein (RKIP) deficiency decreases latency of tumorigenesis and increases metastasis in a murine genetic model of prostate cancer. Prostate 2015;75:292-302.

15 Chatterjee D, Bai Y, Wang Z, Beach S, Mott S, Roy R, Braastad C, Sun Y, Mukhopadhyay A, Aggarwal BB, Darnowski J, Pantazis P, Wyche J, Fu Z, Kitagwa Y, Keller ET, Sedivy JM, Yeung KC: RKIP sensitizes prostate and breast cancer cells to drug-induced apoptosis. J Biol Chem 2004;279:17515-17523.

16 Bushati N, Cohen SM: MicroRNA functions. Annu Rev Cell Dev Biol 2007;23:175-205.

17 Wu W, Sun M, Zou GM, Chen J: MicroRNA and cancer: Current status and prospective. Int J Cancer 2007;120:953-960.

18 Kala R, Peek GW, Hardy TM, Tollefsbol TO: MicroRNAs: An emerging science in cancer epigenetics. J Clin Bioinforma 2013;3:6.

19 Skaftnesmo KO, Prestegarden L, Micklem DR, Lorens JB: MicroRNAs in tumorigenesis. Curr Pharm Biotechnol 2007;8:320-325.

20 Gordeladze JO, Djouad F, Brondello JM, Noel D, Duroux-Richard I, Apparailly F, Jorgensen C: Concerted stimuli regulating osteo-chondral differentiation from stem cells: Phenotype acquisition regulated by microRNAs. Acta Pharmacol Sin 2009;30:1369-1384. 


\section{Cellular Physiology Cell Physiol Biochem 2017;41:1135-1146 \begin{tabular}{ll|l|l|l} 
DOI: 10.1159/000464120 & 2017 The Author(s). Published by S. Karger AG, Basel \\
and Biochemistry & Published online: February 28, 2017 www.karger.com/cpb
\end{tabular} \\ Du et al.: MiR-543 and RKIP in Prostate Cancer}

21 Zhou L, Xu Z, Ren X, Chen K, Xin S: MicroRNA-124 (MiR-124) inhibits cell proliferation, metastasis and invasion in colorectal cancer by downregulating Rho-Associated protein kinase 1(ROCK1). Cell Physiol Biochem 2016;38:1785-1795.

22 Zhao S, Han J, Zheng L, Yang Z, Zhao L, Lv Y: MicroRNA-203 regulates growth and metastasis of breast cancer. Cell Physiol Biochem 2015;37:35-42.

23 Song N, Liu H, Ma X, Zhang S: Placental growth factor promotes metastases of ovarian cancer through MiR543-regulated MMP7. Cell Physiol Biochem 2015;37:1104-1112.

-24 Bertoli G, Cava C, Castiglioni I: MicroRNAs as biomarkers for diagnosis, prognosis and theranostics in prostate cancer. Int J Mol Sci 2016;17:421.

25 Wu X, Wu G, Wu Z, Yao X, Li G: MiR-200a suppresses the proliferation and metastasis in pancreatic ductal adenocarcinoma through downregulation of DEK gene. Transl Oncol 2016;9:25-31.

-26 Bijnsdorp IV, Hodzic J, Lagerweij T, Westerman B, Krijgsman O, Broeke J, Verweij F, Nilsson RJ, Rozendaal L, van Beusechem VW, van Moorselaar JA, Wurdinger T, Geldof AA: MiR-129-3p controls centrosome number in metastatic prostate cancer cells by repressing CP110. Oncotarget 2016;7:16676-16687.

27 Yu L, Zhou L, Cheng Y, Sun L, Fan J, Liang J, Guo M, Liu N, Zhu L: MicroRNA-543 acts as an oncogene by targeting PAQR3 in hepatocellular carcinoma. Am J Cancer Res 2014;4:897-906.

28 Lee S, Yu KR, Ryu YS, Oh YS, Hong IS, Kim HS, Lee JY, Kim S, Seo KW, Kang KS: MiR-543 and miR-590$3 \mathrm{p}$ regulate human mesenchymal stem cell aging via direct targeting of AIMP3/p18. Age (Dordr) 2014;36:9724.

-29 Rao X, Huang X, Zhou Z, Lin X: An improvement of the $2^{\wedge}$ (-delta delta CT) method for quantitative real-time polymerase chain reaction data analysis. Biostat Bioinforma Biomath 2013;3:71-85.

-30 Sridhar SS, Freedland SJ, Gleave ME, Higano C, Mulders P, Parker C, Sartor O, Saad F: Castration-resistant prostate cancer: From new pathophysiology to new treatment. Eur Urol 2014;65:289-299.

-31 Sturge J, Caley MP, Waxman J: Bone metastasis in prostate cancer: Emerging therapeutic strategies. Nat Rev Clin Oncol 2011;8:357-368.

-32 Okato A, Goto Y, Kurozumi A, Kato M, Kojima S, Matsushita R, Yonemori M, Miyamoto K, Ichikawa T, Seki $\mathrm{N}$ : Direct regulation of LAMP1 by tumor-suppressive microRNA-320a in prostate cancer. Int J Oncol 2016;49:111-122.

33 Lin Y, Liu AY, Fan C, Zheng H, Li Y, Zhang C, Wu S, Yu D, Huang Z, Liu F, Luo Q, Yang CJ, Ouyang G: MicroRNA33b inhibits breast cancer metastasis by targeting HMGA2, SALL4 and twist1. Sci Rep 2015;5:9995.

-34 Bing L, Hong C, Li-Xin S, Wei G: MicroRNA-543 suppresses endometrial cancer oncogenicity via targeting FAK and TWIST1 expression. Arch Gynecol Obstet 2014;290:533-541.

35 Fan C, Lin Y, Mao Y, Huang Z, Liu AY, Ma H, Yu D, Maitikabili A, Xiao H, Zhang C, Liu F, Luo Q, Ouyang G: MicroRNA-543 suppresses colorectal cancer growth and metastasis by targeting KRAS, MTA1 and HMGA2. Oncotarget 2016;7:21825-21839.

-36 Park S, Yeung ML, Beach S, Shields JM, Yeung KC: RKIP downregulates B-Raf kinase activity in melanoma cancer cells. Oncotarget 2005;24:3535-3540.

-37 Yeung KC, Rose DW, Dhillon AS, Yaros D, Gustafsson M, Chatterjee D, McFerran B, Wyche J, Kolch W, Sedivy JM: Raf kinase inhibitor protein interacts with NF-kappaB-inducing kinase and TAK1 and inhibits NFkappaB activation. Mol Cell Biol 2001;21:7207-7217.

-38 Woods IK, Grewal NK, Markwart SM, Vellaichamy A, Chinnaiyan AM, Yeung K, Ray ME, Keller ET: Loss of Raf kinase inhibitory protein induces radioresistance in prostate cancer. Int J Radiat Oncol Biol Phys 2008;72:153-160.

-39 Yoshida BA, Sokoloff MM, Welch DR, Rinker-Schaeffer CW: Metastasis-suppressor genes: A review and perspective on an emerging field. J Natl Cancer Inst 2000;92:1717-1730. 